\title{
CORRELATIONS AMONG MICROFIBRIL ANGLE, DENSITY, MODULUS OF ELASTICITY, MODULUS OF RUPTURE AND SHRINKAGE IN 6-YEAR-OLD Eucalyptus urophylla $\times$ E. grandis
}

\author{
P.R.G. Hein ${ }^{\star}$ J.R.M. Silva ${ }^{1}$, L. Brancheriau ${ }^{2}$
}

\begin{abstract}
The cellulose microfibril angle (MFA) in the cell wall is known to have major effects on wood stiffness and shrinkage. However, its influence on juvenile wood traits is not fully understood, especially in Eucalyptus. The aim of this study was to evaluate the relationships among MFA, density ( $\rho$ ), dynamic modulus of elasticity (E), modulus of rupture (MOR), and shrinkage $(\delta)$ in 6-year-old Eucalyptus urophylla $\times E$. grandis. Small clear specimens $(\mathrm{L} 410 \mathrm{~mm} \times \mathrm{R} 25 \mathrm{~mm} \times \mathrm{T} 25 \mathrm{~mm}$ ) were cut from central boards for the determination of $\mathrm{E}$ and MOR. Cubic samples $\left(25 \mathrm{~mm}^{3}\right)$ were removed after the dynamic and static tests to evaluate $\rho$ and $\delta$. MFA was finally measured by X-ray diffraction on small strips coming from the cubic samples. A quasi-absence of statistical link was found for MFA - $\delta$ and MFA - $\rho\left(R^{2}<0.20\right)$. The parameter $\rho /$ MFA was used to estimate $E\left(R^{2}=0.66\right)$ and MOR $\left(R^{2}=0.37\right)$. In a next step, the additive and interaction effects were investigated using multiple linear regressions with a forward selection method. The property $\mathrm{E}$ was found to be linked only with the additive effects of $\rho$ and $1 /$ MFA $\left(R^{2}=0.76\right)$. The additive and interaction effects were all significant for $M O R\left(R^{2}=0.54\right)$. This study showed that a general model including both additive and interaction effects should be used for the prediction of the modulus of elasticity and the modulus of rupture.
\end{abstract}

Keywords: Eucalyptus, microfibril angle, $\mathrm{x}$-ray diffraction, dynamic modulus, modulus of rupture.

\section{INTRODUCTION}

The orientation of cellulose microfibril (MFA) in the cell wall along the fibre axis is known to play a major effect on wood stiffness (Cave 1968) and on drying shrinkage (Meylan 1967). MFA is thus of key importance for wood quality. For example, lumber with a large MFA has a low modulus of elasticity, which reduces its value as a raw material and also its economic value (Walker and Butterfield 1995). According to Lichtenegger et al. (1999) a higher MFA results in a lower stiffness but also goes along with a higher toughness of wood which makes young trees less prone to failure. This concern was not too serious in the past when the forest companies allowed the trees to reach their maturity before harvesting them (Barnett and Bonham 2004).

In conifers, MFA varies from the pith to the bark with the highest angles occurring in the juvenile wood. MFA is also larger at the base of the tree than at the top for a given annual ring. However, the radial variation is more pronounced than the height variation of the MFA. Similar trends are observed in hardwoods, but there are fewer data on the within-tree variation and most of the data concern the Eucalyptus (Donaldson 2008).

${ }^{1}$ Ciência e Tecnologia da Madeira - Departamento de Ciências Florestais.

Universidade Federal de Lavras - campus universitário - Lavras, Minas Gerais, Brazil - CEP 37200-000

${ }^{2}$ CIRAD. Production and Processing of Tropical and Mediterranean Woods. Montpellier, France. loic.brancheriau@cirad.fr

^Corresponding author: paulohein@dcf.ufla.br

Received: 30.04. 2012 Accepted: 23.09. 2012 
Eucalyptus is one of the most widely cultivated hardwood genera in tropical and subtropical areas of the world. The plantations cover about 19.5 million hectares (Iglesias-Trabado and Wilstermann 2008) of which 4.5 millions are in Brazil (ABRAF 2010). Eucalyptus grandis $\times$ urophylla is an important hybrid for plantation forestry in Brazil. The plantations are managed on short rotation ( $\sim 6$ years) to maximize the production of raw material (Raymond 2002). The wood production is used for pulp and paper and also for energy purposes. For instance, the vegetable charcoal is used in metallurgical operations as a reducing agent, especially by the Brazilian steel industries in order to reduce iron ore. In this context, the mechanical traits of wood are important because the charcoal supports the weight of the iron feedstock during oxydo-reduction reactions at elevated temperature (higher to $1500^{\circ} \mathrm{C}$ ).

On the other hand, besides increasing the volume production, the tree breeders are alert to issues of trees survival: the trees have to be stiff enough to support the bending movements caused by the wind for example. Hence, MFA and its relationships with wood mechanical traits of trees from fast-growing plantation can be a critical subject.

Few studies have addressed this issue in hardwoods, so there is a need to extend the range of species that have been investigated (Donaldson 2008). Specifically in the genus Eucalyptus, the effects of microfibril angle on wood properties other than mechanical ones are rarely reported in the literature (Lima et al. 2004, Hein and Lima 2012). Evans and Ilic (2001) and Yang and Evans (2003) have investigated the relationship between MFA, density and modulus of elasticity in Eucalyptus (E. delegatensis, E. globulus, E. nitens and E. regnans from trees between 15 and 31 years of age). They demonstrated that the density and MFA had significant and independent effects on the modulus of elasticity. MFA was the prime determinant but the ratio density/MFA was found to be linearly linked to the modulus and better correlated.

The primary aim of this study was to generate a better understanding about the relationship between MFA and wood traits. Here, the relationships between MFA with density, modulus of elasticity, modulus of rupture and shrinkage in 6-year-old Eucalyptus wood were examined. The influence of MFA and density on wood stiffness and wood strength was also investigated.

\section{MATERIAL AND METHODS}

\section{Material origin and wood sample preparation}

One hundred Eucalyptus urophylla $\times$ E. grandis trees (6-year-old) from clonal tests established for pulpwood production in Brazil (19 $17^{\prime} \mathrm{S}, 42^{\circ} 23^{\prime} \mathrm{W}$, and altitude $230-500 \mathrm{~m}$ ) were evaluated. The details of wood sampling are given in Hein et al. (2010). The trees had a mean circumference at breast height of 62 centimeters and a mean height of 23 meters.

Two hundred and thirty clear wood specimens were cut from central boards $(25 \mathrm{~mm} \times 25 \mathrm{~mm} \times 410$ $\mathrm{mm}$ in the $\mathrm{R}, \mathrm{T}$ and $\mathrm{L}$ axis). After cutting, they were conditioned in a climatic room at $20^{\circ} \mathrm{C}$ and $65 \%$ of relative air humidity to maintain the moisture content constant at a theoretical value of $12 \%$. The specimens were submitted to dynamic and static tests for obtaining the dynamic modulus of elasticity (E) and the modulus of rupture (MOR), respectively. A small cubic sample $\left(25 \mathrm{~mm}^{3}\right)$ was then removed from the intact part of each specimen for the determination of the density $(\rho)$, the radial shrinkage $(\delta \mathrm{rd})$ and the tangential shrinkage ( $\delta \mathrm{tg}$ ). Finally, a radial section of $2 \mathrm{~mm}$ thick was cut from the cubic sample for the X-ray diffraction analysis and the MFA estimation (Figure 1). 
100 trees
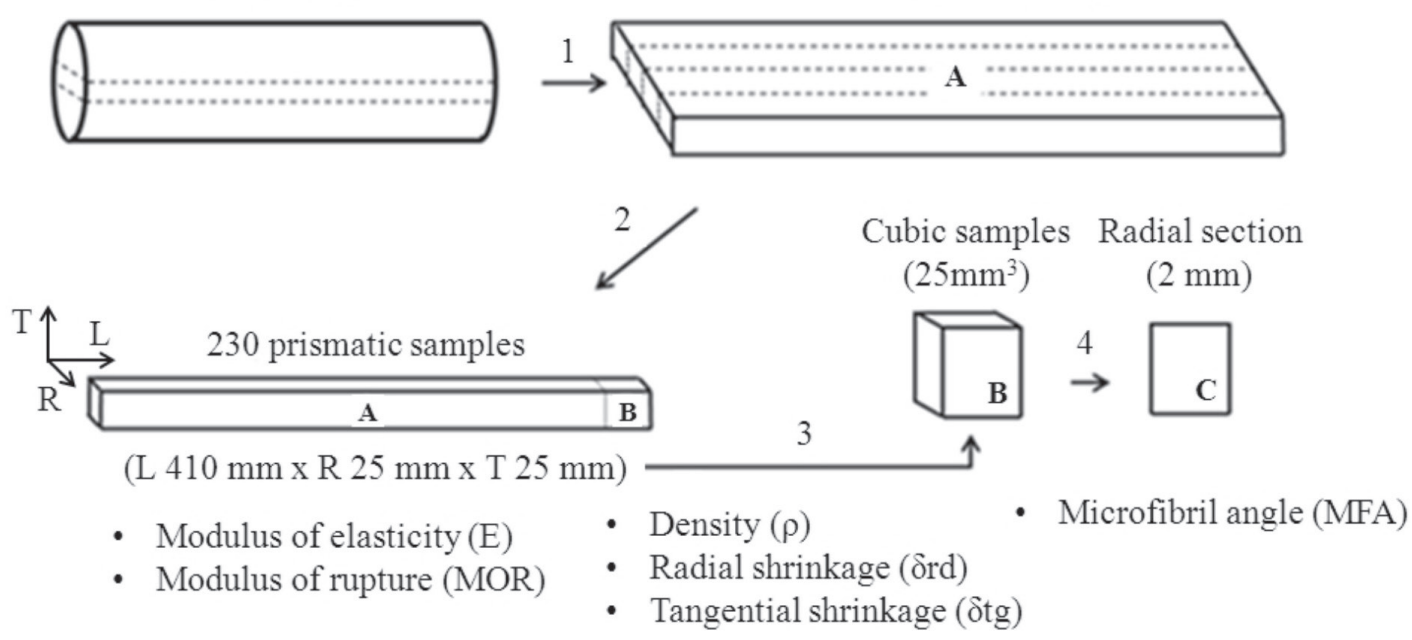

Central boards

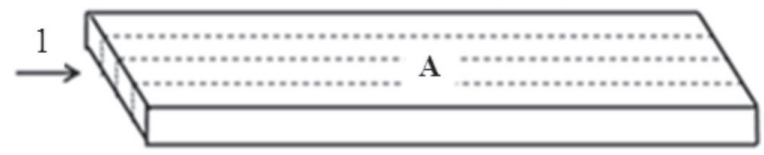

bic samples Radial section

Figure 1. Sampling procedure and measurement protocol.

\section{Dynamic test}

The dynamic tests used to evaluate the elastic properties of the wood samples were previously described in Hein et al. (2010) and were based on acoustic resonance (Brancheriau and Baillères 2002, 2003). In flexural vibration, the first four frequencies were recorded for estimating the dynamic flexural modulus of elasticity $\left(\mathrm{E}_{\mathrm{F}}\right)$ which represents its stiffness under bending stress. In longitudinal vibrations, the first frequency was used for estimating the dynamic longitudinal modulus of elasticity $\left(\mathrm{E}_{\mathrm{L}}\right)$ which represents its stiffness under compressive stress. The analysis of the frequency spectra, the selection of the natural frequencies of vibration and the estimates of $\mathrm{E}$ were performed using the BING ${ }^{\circledR}$ software (CIRAD, Montpellier, France, version 9.1.3) according to the parameters proposed by Brancheriau et al. (2010). The measurement errors associated with the dynamic modulus were lower than $5 \%$.

\section{Static test}

The modulus of rupture (MOR) was obtained by means of a 4-point bending test according to an adaptation of the ASTM standard D198-02 (2003). A universal testing machine Adamel Lhomargy (model DY 36) was used. The load was applied in the tangential direction of the specimen. The span between the supports was $\mathrm{L}=320 \mathrm{~mm}$. The distance between the two loading points was $\mathrm{a}=160 \mathrm{~mm}$. The ultimate load at failure was recorded and the MOR value was determined (1).

$$
M O R=\frac{3 \times P \times(L-a)}{2 \times b \times h^{2}}
$$

with $P$ : the maximum load, $b$ : the width of the beam, $h$ : the depth of the beam.

\section{Wood density and shrinkage measurement}

The density $(\rho)$ and the shrinkages ( $\delta \mathrm{rd}, \delta \mathrm{tg}$ ) of the wood samples were measured according to the ASTM standard D143-09 (2004). The samples, at a moisture content of 12\%, were weighed and their volume was determined by measuring the dimensions with a digital caliper. The density was computed. The samples were then soaked in water to reach the saturation. A digital caliper was used again to measure precisely the sample dimensions. Subsequently, the samples were oven-dried at $103^{\circ} \mathrm{C}$ and their dimensions were measured. Thus, the radial and tangential shrinkage of wood were calculated. 


\section{Microfibril angle by means of $X$-ray diffraction}

The radial sections (Figure 1, sample C) were used for the microfibril angle measurements. All X-ray diffraction data were collected with a Gemini-S diffractometer (Agilent Technologies, Yarnton, UK) with a $\mathrm{CuK} \alpha$ radiation. The diffraction patterns were integrated between $2 \theta=21.5^{\circ}$ and $23.5^{\circ}$ for an azimuth of $360^{\circ}$ in order to plot the intensity diagram of the (200) crystal plane. The angle $T$ was obtained from the diffraction intensity of the (200) arc. An automatic procedure allowed the determination of this parameter which was related to the width of the diffraction arc (Cave 1966). The formula proposed by Yamamoto (1993) was applied to estimate the mean MFA based on the X-ray measurements (2).

$$
M F A=1.575 \times 10^{-3} \times T^{3}-1.431 \times 10^{-1} \times T^{2}+4.693 \times T-36.19
$$

The $T$ parameter is affected by the cross-sectional shape of the cells. Considering the genus Eucalyptus, the fibers are cylindrical and the cross-sectional shape of the cells was considered to remain constant. This hypothesis was verified by repeatability tests which permitted the determination of the measurement error. The measurement error of the $T$ parameter was $3 \%\left( \pm 0.6^{\circ}\right)$.

\section{Statistical analysis}

The descriptive statistics, bivariate correlations and multiple regressions were performed using the R statistical software (version 2.13.0, 2011).

\section{RESULTS AND DISCUSSION}

\section{Descriptive statistics}

Table 1 presents the statistical summary of the measured properties. The specific modulus (E') were added in the table and calculated as the ratio between the dynamic modulus and the density. In material science, this characteristic is mainly used to select material (in this case, species of wood) which can be utilized in order to construct structures with low weight and high stiffness. The mean value of $\mathrm{E}_{\mathrm{L}}(13.4$ $\mathrm{GPa}$ ) was significantly higher than $\mathrm{E}_{\mathrm{F}}(12.5 \mathrm{GPa})$. This phenomenon was explained by the Poisson's effect in longitudinal vibration (lateral motion of matter) coupled with the viscoelastic effect (more pronounced at high frequencies in the case of longitudinal vibration) (Rayleigh 1877, Haines et al. 1996). Furthermore, the equations used for estimating the dynamic modulus assumed an isotropic-homogeneous material and no biological material meets these assumptions. As a consequence, the mean values of specific modulus $\left(\mathrm{E}_{\mathrm{L}}{ }_{\mathrm{L}}\right.$ and $\left.\mathrm{E}_{\mathrm{F}}{ }_{\mathrm{F}}\right)$ were also significantly different. The values of $\mathrm{E}_{\mathrm{L}}$ and $\mathrm{E}_{\mathrm{F}}$ were highly correlated ( $\mathrm{r}=0.97$, not shown) as well as the corresponding specific modulus ( $\mathrm{r}=0.94$, not shown). The wood samples swells $7.8 \%$ (tangentially) and $4.8 \%$ (radially) from the oven-dried condition to the fiber saturation point condition. The anisotropy of shrinkage and swelling is well known and the greatest dimensional change occurs in the tangential direction. The tangential shrinkage is approximately two times greater than the radial one (Glass and Zelinka 2010). The variation range of MFA $\left(8.2^{\circ}\right.$ to $\left.24.3^{\circ}\right)$ was in good agreement with the values reported by Yang and Evans (2003). Furthermore, it was observed that the dispersion of the density and the specific modulus ( $\mathrm{CV}$ of $\sim 13 \%$ ) were almost two times lower than those of elastic modulus, MFA and MOR (CV of $\sim 22 \%$ ). 
Table 1. Descriptive statistics for the density $\left(\rho, \mathrm{kg} / \mathrm{m}^{3}\right)$, dynamic modulus of elasticity (E, MPa), specific modulus (E', GPa), radial and tangential shrinkages ( $\delta$ rd and $\delta \operatorname{tg}, \%$ ), microfibril angle $\left(\mathrm{MFA}^{\circ}\right)$, and modulus of rupture (MOR, $\left.\mathrm{MPa}\right)$.

\begin{tabular}{cccccc}
\hline & Mean & Minimum & Maximum & CV & N \\
\hline$\rho$ & 520 & 363 & 708 & 12.5 & 228 \\
$\mathrm{E}_{\mathrm{L}}$ & 13,438 & 6,522 & 20,785 & 21.2 & 227 \\
$\mathrm{E}_{\mathrm{L}}$ & 25.7 & 16.9 & 32.4 & 13.4 & 227 \\
$\mathrm{E}_{\mathrm{F}}$ & 12,530 & 5,930 & 18,732 & 20.9 & 228 \\
$\mathrm{E}_{\mathrm{F}}$ & 23.9 & 15.3 & 30.6 & 13.5 & 228 \\
$\delta \mathrm{rd}$ & 4.8 & 1.8 & 10.4 & 29.1 & 222 \\
$\delta$ tg & 7.8 & 3.2 & 13.4 & 20.4 & 221 \\
MFA & 12.1 & 8.2 & 24.3 & 21.2 & 220 \\
MOR & 73 & 15 & 119 & 22.0 & 197
\end{tabular}

$\mathrm{E}_{\mathrm{L}}$ and $\mathrm{E}_{\mathrm{F}}$ are the modulus of elasticity obtained by longitudinal and flexural vibration tests. $\mathrm{CV}$ is the coefficient of variation (\%).

\section{Correlations among wood traits}

Table 2. Coefficients of correlation.

\begin{tabular}{cccccccc}
\hline & $\rho$ & $\mathrm{E}_{\mathrm{L}}$ & $\mathrm{E}_{\mathrm{L}}{ }_{\mathrm{L}}$ & $\delta \mathrm{rd}$ & $\delta \operatorname{tg}$ & $\mathrm{MFA}$ & $\rho / \mathrm{MFA}$ \\
\hline $\mathrm{E}_{\mathrm{L}}$ & 0.82 & 1 & & & & & \\
$\mathrm{E}_{\mathrm{L}}{ }_{\mathrm{L}}$ & 0.38 & 0.83 & 1 & & & & \\
$\delta \mathrm{rd}$ & 0.39 & 0.40 & 0.28 & 1 & & & \\
$\delta \mathrm{tg}$ & 0.43 & 0.44 & 0.29 & - & 1 & & \\
MFA & -0.40 & -0.61 & -0.65 & -0.24 & -0.33 & 1 & \\
$\rho / \mathrm{MFA}$ & - & 0.82 & - & 0.36 & 0.43 & -0.84 & 1 \\
MOR & 0.68 & 0.81 & 0.66 & 0.29 & 0.29 & -0.47 & 0.61 \\
\hline
\end{tabular}

Coefficients of correlation for linear relationships between the measured properties were presented in table 2 . The correlations were statistically significant at a level of $1 \%$. The magnitudes of the correlations for longitudinal and flexural elastic modulus or specific modulus with wood traits were similar, thus only the longitudinal properties were presented in this table.

There are numerous statements that density is the most important characteristic in determining the properties of wood (Zobel and Van Buijtenen 1989, Walker and Butterfield 1996, Glass and Zelinka 2010) since it is related to many mechanical traits including modulus of elasticity and rupture. The density of the solid wood substance is very similar in all species and is about $1500 \mathrm{~kg} / \mathrm{m}^{3}$ (Kollmann and Côté 1968). Wood density is thus mainly due to the thickness of the cell walls. As density increases, strength properties increase because internal stresses are distributed among more matter. As expected, 
the density was found to be highly correlated with the wood stiffness ( $\mathrm{r}=0.82$, Table 2$)$ and the wood strength (r=0.68). Early studies on Eucalyptus wood have reported strong correlations between these traits. For instance, Evans and Ilic (2001) found similar relationship between density and modulus of elasticity (r=0.84 with Eucalyptus delegatensis). Yang and Evans (2003) reported equivalent values of correlation between density - modulus of elasticity $(\mathrm{r}=0.90)$ and density - modulus of rupture $(\mathrm{r}=0.89)$ combining data of Eucalyptus globulus, E. nitens and E. regnans.

However, the density does not explain alone the mechanical behavior of wood because wood is a reinforced composite material at two levels: the macroscopic level (cellular organization) and the microscopic level (cell wall organization and chemical composition). At the microscopic scale, the microfibrils are a grouping of rigid cellulose chains analogous to the steel reinforcing bars in reinforced concrete. MFA was negatively correlated to the modulus of elasticity ( $r=-0.61$, Table 2$)$ and, to a less extent, to the modulus of rupture $(\mathrm{r}=-0.47)$. Large microfibril angles had an effect on the stiffness and caused a lower wood strength. According to Donaldson (2008), maximum longitudinal strain increases from $0.5 \%$ to $11 \%$ as microfibril angle increases from $5^{\circ}$ to $50^{\circ}$. Most of the increased extensibility at higher microfibril angles is due to irreversible deformation of the cell wall. These trends are well known in Eucalyptus wood (Evans et al. 1996, Evans and Ilic 2001, Yang and Evans 2003) as well in other genera. Cown et al. (1999) and Ivkovic et al. (2009) reported similar correlations between MFA - modulus of elasticity and MFA - modulus of rupture in Pinus. Treacy et al. (2000) found a linear relationship between these properties in Picea wood samples. However, Yang and Evans (2003) showed a non-linear trend between MFA and the modulus of elasticity combining the data of three Eucalyptus species. They suggested to use the ratio density/MFA and showed that the obtained relationship with the modulus of elasticity was linear $(\mathrm{r}=0.96)$. This parameter was thus added in table 2 (discussed in the next section).

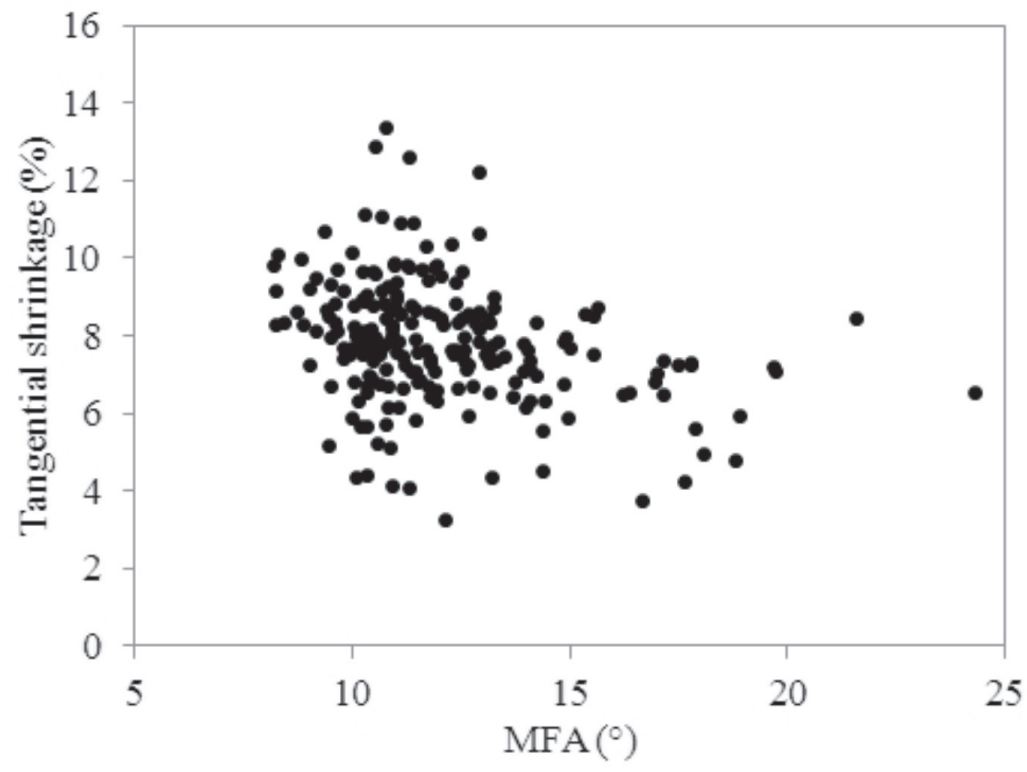

Figure 2. Scatterplot between microfibril angle and tangential shrinkage $\left(\mathrm{R}^{2}=0.11, \mathrm{~N}=220\right)$.

Microfibril orientation within cell walls influences the anisotropic shrinkage during drying (Kollmann and Côté 1968). When the MFA is small, most shrinkage takes place transversely while as the MFA increases, the longitudinal component of the shrinkage increases in a highly non-linear manner. The dimensions of the cellulose microfibrils do not change; it is the matrix of the cell wall which varies with the moisture content (hemicellulose). The cellulose microfibrils act to restrain the matrix from shrinkage in the direction parallel to the microfibril angle (Barnett and Jeronimidis 2003). Such phenomenon is 
responsible for some degrade on drying; especially crook (Walker and Butterfield 1996). Few studies have reported the influence of microfibril orientation on the shrinkage of Eucalyptus wood due to the narrow range of MFA variation. Very low correlations were found between MFA and shrinkages ( $\mathrm{r}=-$ 0.24 in the radial axis, $r=-0.33$ in the tangential axis, Table 2). The MFA x shrinkage plot did not show a clear trend (Figure 2). The works of Meylan (1968) and Yamamoto et al. (2001) reported a strong influence of the MFA on the wood shrinkage for a range from $30^{\circ}$ to $50^{\circ}$. In this study, the maximum value of MFA was $24^{\circ}$ which explained the quasi-absence of relationship between MFA and shrinkages.

\section{Influence of MFA and density on wood stiffness and strength}

After the previous studies presented by Evans and Ilic (2001) and Yang and Evans (2003), the parameter $\rho /$ MFA has been used for explaining the wood stiffness. This parameter predicted the modulus of elasticity with a linear modeling better than MFA and density alone (non-linear trends). For example, McLean et al. (2010) recently demonstrated that $76 \%$ of the variation in modulus of elasticity was explained by the factor $\rho /$ MFA in wood samples of Picea.

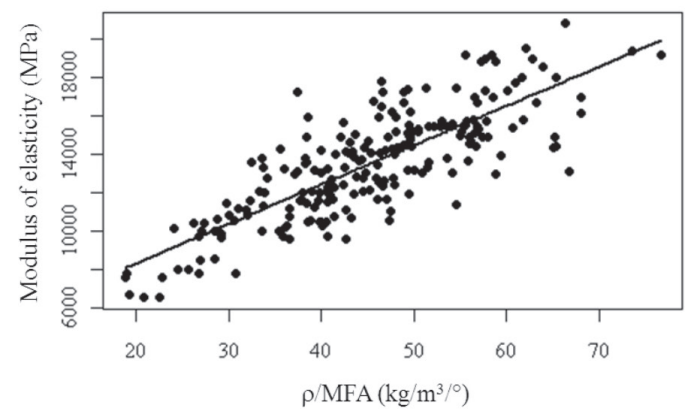

(a)

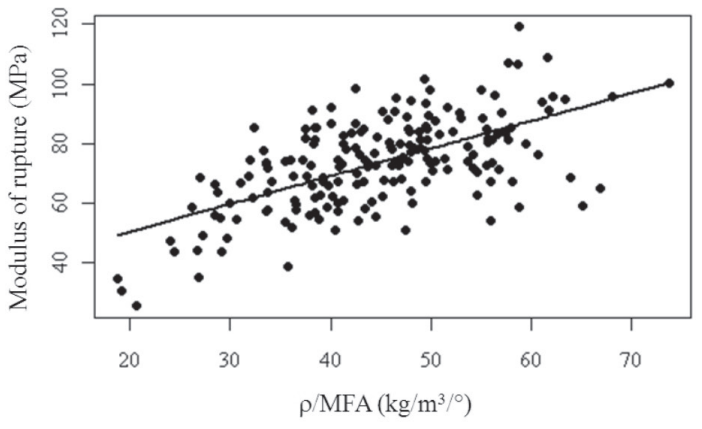

(b)

Figure 3. Relationships between ratio density/microfibril angle and (a) modulus of elasticity $\left(\mathrm{R}^{2}=0.66, \mathrm{~N}=220\right)$, (b) modulus of rupture $\left(\mathrm{R}^{2}=0.37, \mathrm{~N}=197\right)$.

The relationships between $\rho /$ MFA and the mechanical properties were presented at Figure 3 . The linear trends were statistically significant. The model equation for the modulus of elasticity was: $\mathrm{E}_{\mathrm{L}}(\mathrm{GPa})$ $=0.20 \times \rho / M F A+4.3$ with a $95 \%$ confidence interval of $[0.18,0.22]$ for the slope and $[3.3,5.2]$ for the intercept $\left(\mathrm{R}^{2}=0.66\right.$, residual standard error $\left.=1660 \mathrm{MPa}\right)$. The equation associated with the modulus of rupture was: $\operatorname{MOR}(\mathrm{MPa})=0.90 \times \rho / \mathrm{MFA}+33$ with a $95 \%$ confidence interval of $[0.76,1.10]$ for the slope and $[24,40]$ for the intercept $\left(\mathrm{R}^{2}=0.37\right.$, residual standard error $\left.=12 \mathrm{MPa}\right)$. The coefficients found by Yang and Evans (2003) for the modulus of elasticity (slope $=0.21$ and intercept $=3.36$ ) were included in the confidence intervals associated with the model equation $\left(\mathrm{E}_{\mathrm{L}}\right)$. The equation computed in this study was thus equal to the one previously reported (Yang and Evans 2003). The coefficient of determination $\left(\mathrm{R}^{2}=0.66\right)$ was however lower than the one reported $\left(\mathrm{R}^{2}=0.92\right)$. This fact was explained by a scale effect since the mechanical properties were determined from the entire specimens whereas the density and the microfibril angle were determined only on a small part of them. On the other hand, the observed difference in dispersion for the density compared to the microfibril angle and to the mechanical properties might have an effect on the correlation level. 


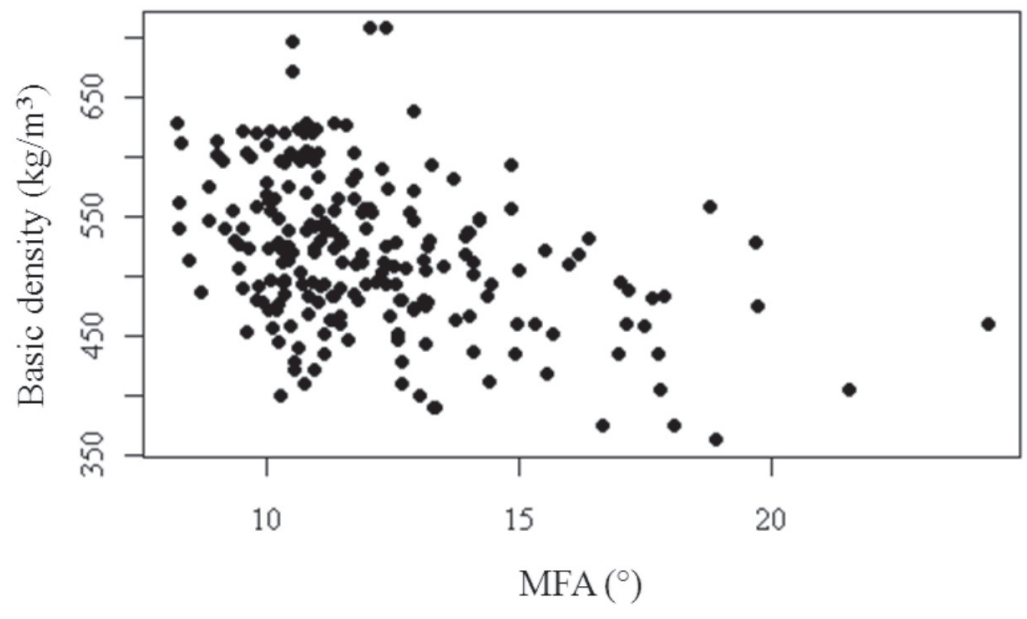

Figure 4. Scatterplot between microfibril angle and density $\left(\mathrm{R}^{2}=0.16, \mathrm{~N}=220\right)$.

In the previous models (Figure 3), the parameter $\rho /$ MFA was an interaction between the density and the inverse of the microfibril angle. These models made the hypothesis that the simultaneous influence of $\rho$ and 1/MFA on the mechanical properties was not additive. The effect of the density were thus moderated or modified by the microfibril angle. Furthermore, these variables should not be linked or a non-linear model with one variable would be more adequate. Figure 4 showed the scatterplot between microfibril angle and density. The correlation coefficient was very low $(\mathrm{r}=-0.40)$ which indicated the quasi-absence of statistical link. The same observation was made with the variable $1 / \mathrm{MFA}(\mathrm{r}=+0.40)$ instead of MFA. According to Donaldson (2008), MFA showed a variable relationship with wood density. This link should be considered as indirect because there is no need of an increment of the fiber wall thickness for modifying the microfibril orientation (for example, the juvenile wood has a low density with a high microfibril angle while the compression wood has a high density with also a high microfibril angle). The main cause of the existence of the link MFA-density should be the radial variation of these properties from juvenile wood to mature wood.

Table 3. Multivariate regression models for predicting the modulus of elasticity and the modulus of rupture with the density $\left(\mathrm{kg} / \mathrm{m}^{3}\right), 1 / \mathrm{MFA}\left({ }^{\circ}{ }^{-1}\right)$ and $\rho / \mathrm{MFA}\left(\mathrm{kg} / \mathrm{m}^{3} /{ }^{\circ}\right)$.

The forward selection method was used. The final estimation of the coefficients and the associated confidence intervals were displayed.

\begin{tabular}{|c|c|c|c|c|c|c|}
\hline Step & Variable & Estimate & $\begin{array}{c}\text { Lower } \\
\text { confidence } \\
\text { limit }(2.5 \%) \\
\end{array}$ & $\begin{array}{c}\text { Upper } \\
\text { confidence } \\
\text { limit }(97.5 \%)\end{array}$ & $\mathrm{r}$ & $\mathrm{R}^{2}$ \\
\hline \multicolumn{7}{|c|}{ Modulus of elasticity (MPa) } \\
\hline 1 & Intercept & -7496 & -9078 & -5914 & & \\
\hline 2 & $\rho$ & 30.7 & 27.6 & 33.8 & 0.82 & 0.68 \\
\hline 3 & 1/MFA & 57983 & 44913 & 71052 & 0.87 & 0.76 \\
\hline \multicolumn{7}{|c|}{ Modulus of rupture (MPa) } \\
\hline 1 & Intercept & -170 & -245 & -94 & & \\
\hline 2 & $\rho$ & 0.44 & 0.29 & 0.59 & 0.68 & 0.47 \\
\hline 3 & 1/MFA & 1873 & 984 & 2761 & 0.71 & 0.51 \\
\hline 4 & $\rho / \mathrm{MFA}$ & -3.3 & -5.0 & -1.5 & 0.74 & 0.54 \\
\hline
\end{tabular}


The hypothesis of the non-additive influence of $\rho$ and 1/MFA on the mechanical properties was investigated by multiple linear regressions (Table 3 ). The additive effects and the interaction were initially taken into account for the modeling. Then the forward selection method was used. This method entered the variables into the model one by one (at each step). At the end of the procedure, only the significant effects were kept in an "optimal" model. The scatterplots of the final models were presented at figure 5.

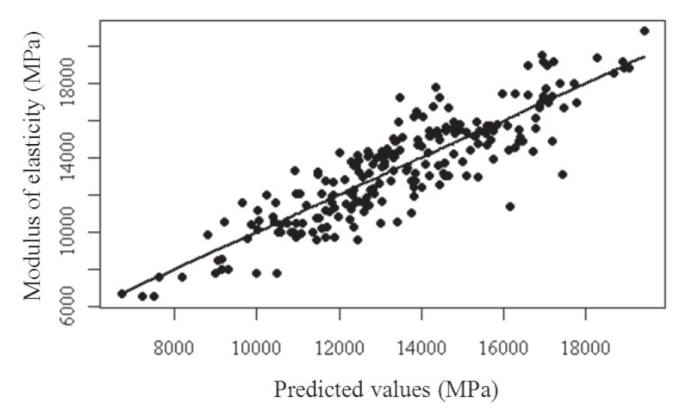

(a)

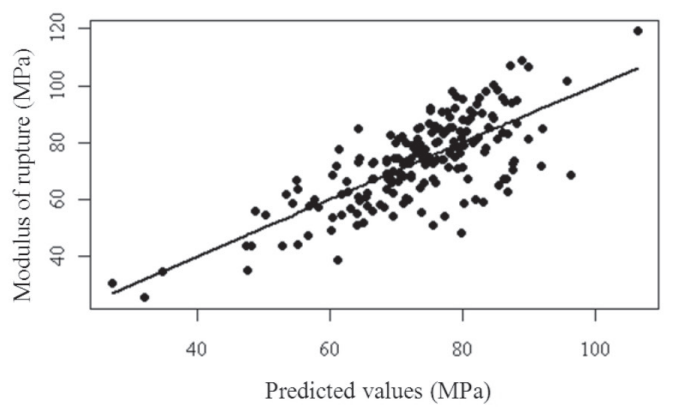

(b)

Figure 5. Predictions of (a) modulus of elasticity $\left(\mathrm{R}^{2}=0.76, \mathrm{~N}=220\right)$ and (b) modulus of rupture $\left(\mathrm{R}^{2}=0.54, \mathrm{~N}=197\right)$ with multivariate regressions.

The modulus of elasticity was found to be linked with the additive effects of density and microfibril angle $\left(\mathrm{R}^{2}=0.76\right.$, residual standard error $=1380 \mathrm{MPa}$, Figure $\left.5-\mathrm{a}\right)$. In this case the interaction term was not significant. The most important effect was the one of the density ( $68 \%$ of the variance) followed in a less extent by the microfibril angle (addition of $8 \%$ in the explained variance). Concerning the modulus of rupture, the additive and interaction effects were all significant $\left(\mathrm{R}^{2}=0.54\right.$, residual standard error $=$ $11 \mathrm{MPa}$, Figure 5-b). The main effect was again the one of the density ( $47 \%$ of the variance) followed by the microfibril angle $(+4 \%)$ and by the interaction term $(+3 \%)$.

Theoretically, the microfibril angle has a predominant effect on wood stiffness (Cave 1966) and numerous studies had verified this argument using experimental data (Walker and Butterfield 1996, Downes et al. 2002, Donaldson 2008). For Eucalyptus, Evans and Ilic (2001) reported that the density variation alone accounted for $70 \%$ of the variation in E. delegatensis samples, while the microfibril angle alone accounted for $86 \%$. Yang and Evans (2003) found a similar result ( $81 \%$ for the density and $87 \%$ for the microfibril angle). Thus, the influence of MFA on wood stiffness was known to be significantly greater than the one of the density. The methods of sampling preparation and measurement should be taken into account for comparing the relationships concerning the density, the microfibril angle, and the modulus of elasticity reported in the previous studies. For instance, Evans and Ilic (2001), Yang and Evans (2003) and McLean et al. (2010) had employed the SilviScan device (Evans et al. 1999) to perform multiple measurements to obtain a mean MFA across a small strip cut from the specimen. In this study, the microfibril orientation was not the main effect which explained the variability of modulus of elasticity and modulus of rupture. The microfibril angle was measured in a single point of a radial section cut from the specimen using a polyvalent $\mathrm{X}$-ray diffractometer. This fact might explain this result. Furthermore, we believe that the way to go further in the analysis would be to measure the mean density and the mean microfibril angle on the entire specimens. A supplementary effect should be taken into account in the analysis: the lignin content. Lignin satisfies the function of a matrix within a composite material (lignin is often considered as an "adhesive"). Thus, lignin should have an influence on the stiffness of wood. 


\section{CONCLUSION}

The relationships between MFA and wood traits were investigated in Eucalyptus from fast grown plantations. A quasi-absence of statistical link was found between MFA and $\delta\left(\mathrm{R}^{2}=0.06\right.$ in the radial axis, $\mathrm{R}^{2}=0.11$ in the tangential axis). The same observation was obtained between MFA and $\rho\left(\mathrm{R}^{2}=0.16\right)$. MFA was significantly correlated to $E\left(R^{2}=0.37\right)$ and, to a less extent, to MOR $\left(\mathrm{R}^{2}=0.22\right)$. Previous studies stated that MFA had a predominant effect on mechanical properties of wood and suggested using the ratio $\rho /$ MFA as predictor. The parameter $\rho /$ MFA was used to estimate $E\left(R^{2}=0.66\right)$ and $M O R\left(R^{2}=0.37\right)$. The equation found in this study was equal to the one previously reported for $\mathrm{E}$. These last models made the hypothesis that the simultaneous influence of $\rho$ and 1/MFA on the mechanical properties was not additive. The additive effects and the interaction effect were investigated using multiple linear regressions with a forward selection method. The property $\mathrm{E}$ was found to be linked only with the additive effects of $\rho$ and $1 / \mathrm{MFA}\left(\mathrm{R}^{2}=0.76\right)$. The most important effect was the one of $\rho(68 \%$ of the variance) followed in a less extent by MFA $(+8 \%)$. The additive and interaction effects were all significant for MOR $\left(\mathrm{R}^{2}=0.54\right)$. The main parameter was $\rho(47 \%$ of the variance) followed by MFA $(+4 \%)$ and by the interaction term $\rho /$ MFA ( $+3 \%)$. This study showed that a general model including both additive effects and interaction effects should be used for the prediction of the modulus of elasticity and the modulus of rupture.

\section{ACKNOWLEDGMENTS}

The authors express their special thanks to the CENIBRA for the plant material; to the Universidade Federal de Lavras (UFLA, Brazil), CIRAD and CNRS (Montpellier, France) for the experimental work. The authors would like to thank Dr. T. ALMÉRAS and Dr. B. CLAIR (LMGC-CNRS) for their help in the X-ray diffraction measurements. This Project was funded by CENIBRA (Celulose Nipo-Brasileira), CNPq (Conselho Nacional de Desenvolvimento Científico e Tecnológico, Brazil) and CIRAD (UPR40). P.R.G. Hein was supported by CNPq (process no. 200970/2008-9). This study was a part of his PhD thesis, defended at University of Montpellier 2 (France) in June 2011.

\section{REFERENCES}

ABRAF. Associação Brasileira de Produtores de Florestas Plantadas. 2010. Statistical Yearbook - Base Year 2009/ ABRAF - Brasília, 127p.

ASTM. American Society for Testing and Materials. 2004. Standard Test Methods for Small Clear Specimens of Timber. D143-09.

ASTM. American Society for Testing and Materials. 2003. Standard Test Methods of Static Tests of Lumber in Structural Sizes. D198-02.

Barnett, J.R.; Bonham, V.A. 2004. Cellulose microfibril angle in the cell wall of wood fibres. Biol Reviews 79(2):461-472.

Barnett, J.R.; Jeronimidis, G. 2003. Wood quality and its biological basis. Blackwell Scientific Publisher, 226p. Oxfordshire, UK

Brancheriau, L.; Baillères, H. 2002. Natural vibration analysis of clear wooden beams: a theoretical review. Wood Sci Technol 36(4):347-365. 
Brancheriau, L.; Baillères, H. 2003. Use of the partial least squares method with acoustic vibration spectra as a new grading technique for structural timber. Holzforschung 57(6):644-652.

Brancheriau, L.; Kouchade, C.; Brémaud, I. 2010. Internal friction measurement of tropical species by various acoustic methods. J Wood Sci 56(5): 371-379.

Cave, I.D. 1966. Theory of X-ray measurement of microfibril angle in wood. Forest Prod $J 16$ (10):37-42.

Cave, I.D. 1968. The anisotropic elasticity of the plant cell wall. Wood Sci Tech 2(4):268-278.

Cown, D.J.; Hebert, J.; Ball, R. 1999. Modelling radiata pine lumber characteristics. Part 1: mechanical properties of small clears. N Z J For 29(2):203-213.

Donaldson, L. 2008. Microfibril angle: measurement, variation and relationships - a review. IAWA $J$ 29(4):345-386.

Downes, G.M.; Nyakuengama, J.G.; Evans, R.; Northway, R.; Blakemore, P.; Dickson, R.L.; Lausberg, M. 2002. Relationship between wood density, microfibril angle and stiffness in thinned and fertilized Pinus radiata. IAWA J 23(3):253-265.

Evans, R.; Stuart, S.A.; Van der Touw, J. 1996. Microfibril angle scanning of increment cores by X-ray diffractometry. Appita J 49(6):411-414.

Evans, R.; Ilic, J. 2001. Rapid prediction of wood stiffness from microfibril angle and density. Forest Prod J 51(3):53-57.

Evans, R. 1999. A variance approach to the x-ray diffractometric estimation of microfibril angle in wood. Appita J 52(4):283-289.

Glass, S.V.; Zelinka, S.L. 2010. Moisture Relations and Physical Properties of Wood. In: Wood handbook - Wood as an engineering material. General Technical Report FPL-GTR-190. Madison, WI: U.S. Department of Agriculture, Forest Service, Forest Products Laboratory. pp. 4.1-4.19

Haines, D.W.; Leban, J.M.; Herbe, C. 1996. Determination of Young's modulus for spruce, fir and isotropic materials by the resonance flexure method with comparisons to static flexure and other dynamic methods. Wood Sci Tech 30 (4): 253-263.

Hein, P.R.G.; Brancheriau, L.; Trugilho, P.F.; Lima, J.T.; Chaix, G. 2010. Resonance and near infrared spectroscopy for evaluating dynamic wood properties. J Near Infrared Spectrosc 18(6):443-454.

Hein, P.R.G.; Lima, J.T. 2012. Relationships between microfibril angle, modulus of elasticity and compressive strength in Eucalyptus wood. Maderas.Ciencia y tecnología 14(3):267-274

Iglesias-Trabado, G.; Wilstermann, D. 2008. Eucalyptus universalis. Global cultivated eucalypt forests map 2008. Version 1.0.1 In GIT Forestry Consulting's Eucalyptologics: Information resources on Eucalyptus Cultivation worldwide. Retrieved from http://www.git-forestry.com/ [accessed March 2011].

Ivković, M.; Gapare, W.J.; Abarquez, A.; Powell, M.B.; Ilic, J.; Wu, H.X. 2009. Prediction of wood stiffness, strength, and shrinkage in juvenile corewood of radiata pine. Wood Sci Technol 43(34):237-257. 
Kollmann, F.R.; Côté, W.A. 1968. Principles of Wood Science and Technology. Springer-Verlag, Berlin, Germany. 592 pp

Lichtenegger, H.; Reiterer, A.; Stanzl-Tschegg, S.E.; Fratzl, P. 1999. Variation of cellulose microfibril angles in softwoods and hardwoods - a possible strategy of mechanical optimization. J Struct Biol 128(3): 257-269.

Lima, J.T.; Breese, M.C.; Cahalan, C.M. 2004. Variation in microfibril angle in Eucalyptus clones. Holzforschung 58(2):160-166.

McLean, J.P.; Evans, R.; Moore, J.R. 2010. Predicting the longitudinal modulus of elasticity of Sitka spruce from cellulose orientation and abundance. Holzforschung 64(4):495-500.

Meylan, B.A. 1967. Measurement of microfibril angle by X-ray diffraction. Forest Prod J 17(5):51-58.

Meylan, B.A. 1968. Cause of high longitudinal shrinkage of wood. Forest Prod J 18(4):75-78.

Rayleigh, J.W.S. 1877. The theory of sound. Macmillan, London. Reprinted in 1967 by Dover Publications, New York. 984 pp

Raymond, C.A. 2002. Genetics of Eucalyptus wood properties. Ann. For. Sci. 59(5-6):525-531.

Treacy, M.; Dhubhain, A.N.; Evertsen, J. 2000. The influence of microfibril angle on modulus of elasticity and modulus of rupture in four provenances of Irish grown Sitka spruce (Picea sitchensis (Bong.) Carr). J Inst Wood Sci 15(4):211-220.

Walker, J.C.F.; Butterfield, B.G. 1996. The importance of microfibril angle for the processing industries. $N Z J$ For 40(4):34-40

Yamamoto, H.; Okuyama, T.; Yashida, M. 1993. Method of determining the mean microfibril angle of wood over a wide range by the improved Cave's method. Mokuzai Gakkaishi 39(2):118-125.

Yamamoto, H.; Sassus, F.; Ninomiya, M.; Gril, J. 2001. A model of anisotropic swelling and shrinking process of wood. Part 2. A simulation of shrinking wood. Wood Sci Technol 35(1-2):167-181.

Yang, J.L.; Evans, R. 2003. Prediction of MOE of eucalypt wood from microfibril angle and density. Holz als Roh- und Werkstoff 61(6):449-452.

Zobel, B.J.; Van Buijtenen, J.P. 1989. Wood Variation: Its Causes and Control. Springer Verlag, Berlin. 363p. 